\title{
Calcium Microdomains Near R-Type Calcium Channels Control the Induction of Presynaptic Long-Term Potentiation at Parallel Fiber to Purkinje Cell Synapses
}

\author{
Michael H. Myoga and Wade G. Regehr \\ Department of Neurobiology, Harvard Medical School, Boston, Massachusetts 02115
}

\begin{abstract}
R-type calcium channels in postsynaptic spines signal through functional calcium microdomains to regulate a calcium/calmodulinsensitive potassium channel that in turn regulates postsynaptic hippocampal long-term potentiation (LTP). Here, we ask whether R-type calcium channels in presynaptic terminals also signal through calcium microdomains to control presynaptic LTP. We focus on presynaptic LTP at parallel fiber to Purkinje cell synapses in the cerebellum (PF-LTP), which is mediated by calcium/calmodulin-stimulated adenylyl cyclases. Although most presynaptic calcium influx is through N-type and P/Q-type calcium channels, blocking these channels does not disrupt PF-LTP, but blocking R-type calcium channels does. Moreover, global calcium signaling cannot account for the calcium dependence of PF-LTP because R-type channels contribute modestly to overall calcium entry. These findings indicate that, within presynaptic terminals, R-type calcium channels produce calcium microdomains that evoke presynaptic LTP at moderate frequencies that do not greatly increase global calcium levels.
\end{abstract}

\section{Introduction}

Calcium can activate proteins within neurons either by widespread but modest increases in global calcium levels $\left(\mathrm{Ca}_{\text {global }}\right)$ or by larger localized calcium increases in microdomains near calcium-permeable channels $\left(\mathrm{Ca}_{\text {local }}\right)$ (Fogelson and Zucker, 1985; Simon and Llinas, 1985; Augustine and Neher, 1992; Stern, 1992; Zucker and Regehr, 2002; Berridge, 2006; Rizzuto and Pozzan, 2006; Higley and Sabatini, 2008). $\mathrm{Ca}_{\text {local }}$ signaling allows specific types of calcium channels to selectively activate calciumactivated potassium channels (BK and SK) (Fakler and Adelman, 2008). Calcium microdomains can also allow calcium sources to initiate calcium-sensitive pathways within cells (Berridge, 2006; Rizzuto and Pozzan, 2006). Although it is straightforward to measure $\mathrm{Ca}_{\text {global }}$ signals with standard fluorescence techniques, measuring calcium signals associated with calcium microdomains is exceedingly difficult. Consequently, there is much left to learn about the regulation of cellular processes by calcium microdomains.

Calcium microdomains have been implicated in the induction of long-term potentiation (LTP). In the spines of hippocampal pyramidal cells, $\mathrm{Ca}_{\text {local }}$ near R-type calcium channels $\left(\mathrm{CaV}_{2.3}\right)$ activate SK channels (Bloodgood and Sabatini, 2007). SK channels also control the magnitude of calcium signals within spines and thereby regulate LTP at the CA3 to CA1 synapse (Stackman

Received 0ct. 6, 2010; revised Jan. 14, 2011; accepted Jan. 20, 2011.

This work was supported by National Institutes of Health Grants DA024090 and R37NS032405 to W.G.R. and DA025450 to M.H.M. We thank M. Antal, A. Best, Y. Chu, J. Crowley, D. Fioravante, C. Hull, S. Jackman, T. Pressler, and M. Thanawala for valuable comments on this manuscript.

Correspondence should be addressed to Wade G. Regehr, Department of Neurobiology, Harvard Medical School, 220 Longwood Avenue, Boston, MA 02115. E-mail: wade_regehr@hms.harvard.edu.

DOI:10.1523/JNEUROSCI.5252-10.2011

Copyright $\odot 2011$ the authors $\quad 0270-6474 / 11 / 315235-09 \$ 15.00 / 0$ et al., 2002; Bond et al., 2004; Ngo-Anh et al., 2005; Hammond et al., 2006). This suggests that functional calcium microdomains near R-type calcium channels can regulate the induction of postsynaptic hippocampal LTP. Such $\mathrm{Ca}_{\text {local }}$ signals can allow a type of calcium channel to strongly influence a neuron, even if it accounts for a small fraction of $\mathrm{Ca}_{\text {global }}$. Although it is known that R-type calcium channels can regulate presynaptic LTP at some synapses (Breustedt et al., 2003; Dietrich et al., 2003), it is not known whether this is a result of spatially localized signaling through calcium microdomains.

Presynaptic LTP mediated by calcium/calmodulin-stimulated adenylyl cyclases (Ca-ACs, type 1 and $8, \mathrm{AC} 1$ and AC8) is well suited to testing this possibility. This form of plasticity has been studied at mossy fiber (MF) synapses onto CA3 pyramidal cells (MF-LTP) (Zalutsky and Nicoll, 1990; Nicoll and Schmitz, 2005), parallel fiber (PF) synapses onto Purkinje cells (PCs) (PF-LTP) (Salin et al., 1996; van Beugen et al., 2006), and other synapses (Maffei et al., 2002; Liu et al., 2004; Fourcaudot et al., 2008; Bender et al., 2009; Wang et al., 2009). Mice that lack AC1 and AC8 do not express either MF-LTP (Wong et al., 1999; Wang et al., 2003) or PF-LTP (Storm et al., 1998) and exhibit deficits in hippocampal and cerebellar behaviors (Wu et al., 1995; Shan et al., 2008; Zhang et al., 2008). MF and PF boutons contain multiple types of voltage-gated calcium channels (P/Q, N, and R) (Castillo et al., 1994; Mintz et al., 1995), but only R-type calcium channels play a crucial role in MF-LTP (Breustedt et al., 2003; Dietrich et al., 2003). It is not known whether R-type calcium channels play a similar role in Ca-AC-dependent LTP at other synapses. With regard to $\mathrm{Ca}_{\text {global }}$ versus $\mathrm{Ca}_{\text {local }}$ signaling, MF-LTP is thought to be triggered by $\mathrm{Ca}_{\text {global }}$ (Dietrich et al., 2003), but the nature of the calcium signal that triggers PF-LTP is not known. This is of particular interest because PF-LTP is readily induced by 
a moderate-frequency train $(8 \mathrm{~Hz}, 15 \mathrm{~s})$ that may not elevate $\mathrm{Ca}_{\text {global }}$ sufficiently to activate Ca-AC (Olwin et al., 1984; Cimler et al., 1985; Masada et al., 2009).

Here, we ask whether R-type calcium channels are important for PF-LTP and whether they signal through $\mathrm{Ca}_{\text {global }}$ or $\mathrm{Ca}_{\text {local }}$. We find that R-type calcium channels play a crucial role in the induction of PF-LTP. Moreover, we find that $\mathrm{Ca}_{\text {global }}$ cannot account for the calcium dependence of PF-LTP. Instead, R-type calcium channels induce PF-LTP by elevating $\mathrm{Ca}_{\text {local }}$ to activate $\mathrm{Ca}-\mathrm{AC}$. These findings indicate that by signaling through functional calcium microdomains, R-type calcium channels can control presynaptic forms of LTP.

\section{Materials and Methods}

Tissue preparation. Animals were handled in accordance with federal guidelines and protocols approved by Harvard University. Sprague Dawley rats (postnatal day 17-19) were deeply anesthetized with isoflurane and decapitated. Brains were removed and placed in an ice-cold dissecting solution containing the following (in $\mathrm{mM}$ ): $82.7 \mathrm{NaCl}, 65$ sucrose, $23.8 \mathrm{NaHCO}_{3}, 23.7$ glucose, $6.8 \mathrm{MgCl}_{2}, 2.4 \mathrm{KCl}, 1.4 \mathrm{NaH}_{2} \mathrm{PO}_{4}$, and 0.5 $\mathrm{CaCl}_{2}$. Parasagittal (for electrophysiology) or transverse (for presynaptic calcium imaging) slices ( $250 \mu \mathrm{m}$ thick) were made from the cerebellum in ice-cold dissecting solution. Slices were then incubated at $32^{\circ} \mathrm{C}$ for 30 min in a saline solution containing the following (in $\mathrm{mM}$ ): $125 \mathrm{NaCl}, 26$ $\mathrm{NaHCO}_{3}, 25$ glucose, $2.5 \mathrm{KCl}, 2 \mathrm{CaCl}_{2}, 1.25 \mathrm{NaH}_{2} \mathrm{PO}_{4}$, and $1 \mathrm{MgCl}_{2}$, adjusted to $315 \mathrm{mOsm}$. Slices were then allowed to equilibrate to room temperature for an additional $30 \mathrm{~min}$. Slices were constantly bubbled with $95 \% \mathrm{O}_{2} / 5 \% \mathrm{CO}_{2}$. Most experiments were performed at $25 \pm 1{ }^{\circ} \mathrm{C}$ and flow rates were $2 \mathrm{ml} / \mathrm{min}$. A few experiments were performed at $34 \pm$ $1^{\circ} \mathrm{C}$ and flow rates were $4 \mathrm{ml} / \mathrm{min}$.

Electrophysiology. Whole-cell recordings of PCs were obtained with borosilicate glass electrodes of $1-1.5 \mathrm{M} \Omega$ resistances. The internal solution contained the following (in mM): $110 \mathrm{Cs}_{2} \mathrm{SO}_{4}, 15 \mathrm{HEPES}, 10 \mathrm{EGTA}$, $5.5 \mathrm{MgSO}_{4}, 4 \mathrm{CaCl}_{2}, 2 \mathrm{Na}_{2}$-ATP, $1 \mathrm{MgCl}_{2}$, and $0.2 \mathrm{D} 600$, adjusted to 315 $\mathrm{mOsm}$ and $\mathrm{pH}$ 7.3. PCs were visualized with a BX51 upright microscope equipped with a $60 \times 0.9$ numerical aperture (NA) water-immersion lens (Olympus). Recordings were made with a Multiclamp 700B amplifier (Molecular Devices). For LTP experiments, two borosilicate glass electrodes (2-3 M $\Omega$ resistances) filled with saline were placed in the molecular layer ( $>75 \mu \mathrm{m}$ apart) to activate independent PF pathways. PFs were stimulated with brief $(0.2 \mathrm{~ms})$ current pulses $(10-25 \mu \mathrm{A})$. This protocol was repeated every $10 \mathrm{~s}$ to evoke EPSCs in PCs. Stimulation to each pathway was staggered by $5 \mathrm{~s}$. To induce LTP, an $8 \mathrm{~Hz}, 15 \mathrm{~s}$ train was delivered to only one pathway. The other pathway was not stimulated during this time. For LTP experiments in the presence of $\omega$-agatoxin IVA, the second electrode was elevated slightly above the slice and connected to ground to reduce the stimulus artifact.

Presynaptic calcium imaging. Calcium transients in PFs were measured as described previously (Regehr and Tank, 1991; Mintz et al., 1995; Regehr and Atluri, 1995). Briefly, Magnesium Green AM (Invitrogen) was pressure loaded into PFs for 5-10 min and then allowed to equilibrate throughout PFs for $1 \mathrm{~h}$. Fluorescence signals were visualized on a BX50 microscope equipped with a $60 \times 0.9$ NA water-immersion lens (Olympus). Magnesium Green AM was excited by a $470 \mathrm{~nm}$ LED (Thorlabs) and fluorescence was detected by a custom-built photodiode. A $50-\mu \mathrm{m}-$ diameter imaging site was selected $>200 \mu \mathrm{m}$ from the loading site. Because the molecular layer is mostly comprised of PFs, this imaging site effectively measures $\mathrm{Ca}_{\text {global }}$ signals in thousands of PFs (Sabatini and Regehr, 1998; Yuste and Konnerth, 2005). A single borosilicate glass electrode filled with saline $(\sim 500 \mathrm{k} \Omega$ resistance) was placed in the molecular layer $>150 \mu \mathrm{m}$ from the imaging site. For low-frequency stimulation, single 0.2 ms $(50-100 \mu \mathrm{A})$ pulses were repeated at $0.1 \mathrm{~Hz}$. Each calcium transient was normalized to the baseline fluorescence and expressed as $\Delta F / F$.

There were several differences in the way calcium transients during 8 $\mathrm{Hz}, 15 \mathrm{~s}$ trains were analyzed. First, the entire fluorescence signal was normalized to the amplitude of the first peak in the train. This allowed us to quantify the buildup of calcium during the train. Second, light exposure was limited to a brief $(20 \mathrm{~ms})$ window around the stimulus to reduce photobleaching. The blanked times between stimuli in the train were extrapolated using a straight line for integral measurements. Finally, 2,3-dioxo-6nitro-1,2,3,4-tetrahydrobenzo[f] quinoxaline-7-sulfonamide (NBQX, 10 $\mu \mathrm{M})$ was included in these experiments.

Pharmacology. All experiments were performed in the presence of picrotoxin $(20 \mu \mathrm{M})$ to block $\mathrm{GABA}_{\mathrm{A}}$-mediated currents. Experiments investigating evoked EPSCs were also performed in the presence of 8-cyclopentyl-1,3dipropylxanthine (DPCPX, $5 \mu \mathrm{M}$ ) to block adenosine A1 receptors, (2S)-3[(15)-1-(3,4-dichlorophenyl)ethyl] amino-2-hydroxypropyl)(phenylmethyl) phosphinic acid (CGP 55845, $2 \mu \mathrm{M}$ ) to block $\mathrm{GABA}_{\mathrm{B}}$ receptors, and $N$-(piperidin-1-yl)-5-(4-iodophenyl)-1-(2,4-dichlorophenyl)-4-methyl-1Hpyrazole-3-carboxamide (AM 251, $2 \mu \mathrm{M}$ ) to block cannabinoid CB1 receptors (CB1Rs). This prevented regulation of presynaptic G-proteincoupled receptor signaling that could regulate $\mathrm{Ca}-\mathrm{AC}$ (van Beugen et al., 2006). Experiments investigating spontaneous miniature EPSCs (mEPSCs) were performed in the presence of octahydro-12-(hydroxymethyl)-2imino-5,9:7,10a-dimethano-10aH-[1,3] dioxocino[6,5-d]pyrimidine4,7,10,11,12-pentol (TTX, $1 \mu \mathrm{M}$ ) to block voltage-gated sodium channels. For experiments using peptide toxins $\omega$-conotoxin GVIA, $\omega$-agatoxin IVA, or SNX-482, recirculation was used to reduce the amount of toxin used. Drugs were dissolved in dimethylsulfoxide at 5000-50,000 times the final concentration except for NBQX, TTX, and peptide toxins, which were dissolved in water at 1000 times the final concentration. All drugs were purchased from Tocris Bioscience, except for $\omega$-conotoxin GVIA and $\omega$-agatoxin IVA, which were from Peptides International, and SNX-482, which was from Alomone Labs. All other chemicals were purchased from Sigma.

Experiments at near-physiological temperatures. Experiments performed at near-physiological temperatures differed from those performed at $25^{\circ} \mathrm{C}$ in the following ways. LTP experiments were performed at $34 \pm 1^{\circ} \mathrm{C}$. In some experiments, LTP was induced with a $30 \mathrm{~s}$ tetanus and DPCPX, CGP 55845, and AM 251 were omitted. Presynaptic calcium imaging experiments were performed at $32 \pm 1{ }^{\circ} \mathrm{C}$ and DPCPX, CGP 55845, and AM 251 were omitted.

Data acquisition and analysis. Data were acquired on a personal computer using an ITC-18 interface (Instrutech) at 10 and $1 \mathrm{kHz}$ for electrophysiology and fluorescence data, respectively. Data were then digitally filtered using an eight-pole Bessel filter at $5 \mathrm{kHz}$ for electrophysiology data and $500 \mathrm{~Hz}$ for fluorescence data. All data were analyzed using Igor Pro (Wavemetrics). Averages are presented as mean \pm SEM. One-way ANOVA or paired Student's $t$ test was performed to determine statistical significance $(p<0.05)$ where indicated.

\section{Results}

\section{LTP at parallel fiber to Purkinje cell synapses is sensitive to} changes in external calcium concentration

We studied PF-LTP by activating two independent PF pathways $(0.1 \mathrm{~Hz})$ (Fig. 1A). Resulting EPSCs were monitored with a whole-cell recording electrode in a PC. A tetanus was delivered to one pathway $(8 \mathrm{~Hz}, 15 \mathrm{~s})$ and the other pathway served as a control. After the tetanus, $0.1 \mathrm{~Hz}$ stimulation of both pathways was resumed. When the external calcium concentration $\left(\mathrm{Ca}_{\mathrm{e}}\right)$ was $2 \mathrm{mM}$, EPSC amplitudes in the tetanized pathway were potentiated by $22 \pm 8 \%$ (Fig. $1 E$, filled circles) and the control pathway was unchanged $(0 \pm 7 \%, n=10, p<0.05$, ANOVA) (Fig. $1 E$, open circles).

We determined the calcium sensitivity of PF-LTP by measuring the magnitude of potentiation in different $\mathrm{Ca}_{\mathrm{e}}$ (Fig. $1 B-D$ ). Reducing $\mathrm{Ca}_{\mathrm{e}}$ decreases influx through calcium channels without discriminating between calcium channel types (Mintz et al., 1995). In $1.5 \mathrm{~mm} \mathrm{Ca}_{\mathrm{e}}$ the tetanized pathway was potentiated $(39 \pm 5 \%)$ compared with the control pathway $(-3 \pm 8 \%, n=8$, $p<0.05$, ANOVA) (Fig. $1 D$ ). Although the magnitude of this potentiation was not significantly different from in $2 \mathrm{mM} \mathrm{Ca}_{\mathrm{e}}$ $(p=0.07)$, it appeared to be somewhat larger, perhaps because it is easier to induce LTP when the initial probability of release is slightly decreased. In contrast, in 1.25 and $1 \mathrm{mM} \mathrm{Ca}_{\mathrm{e}}$, the tetanus 
A

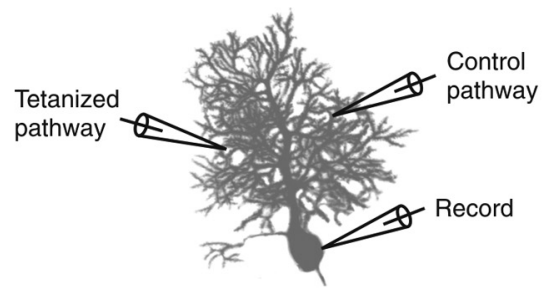

B

- Tetanized pathway

O Control pathway

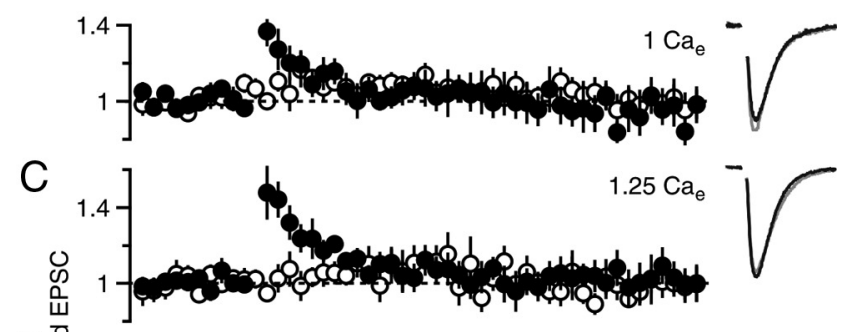

$\mathrm{D}$

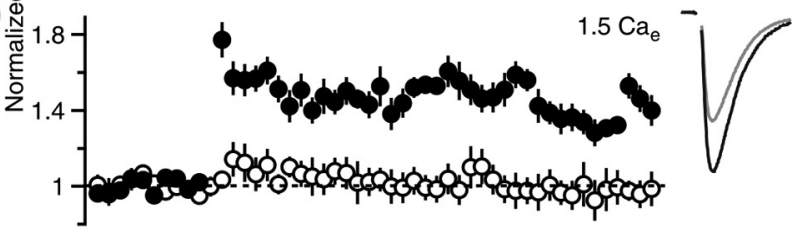

E
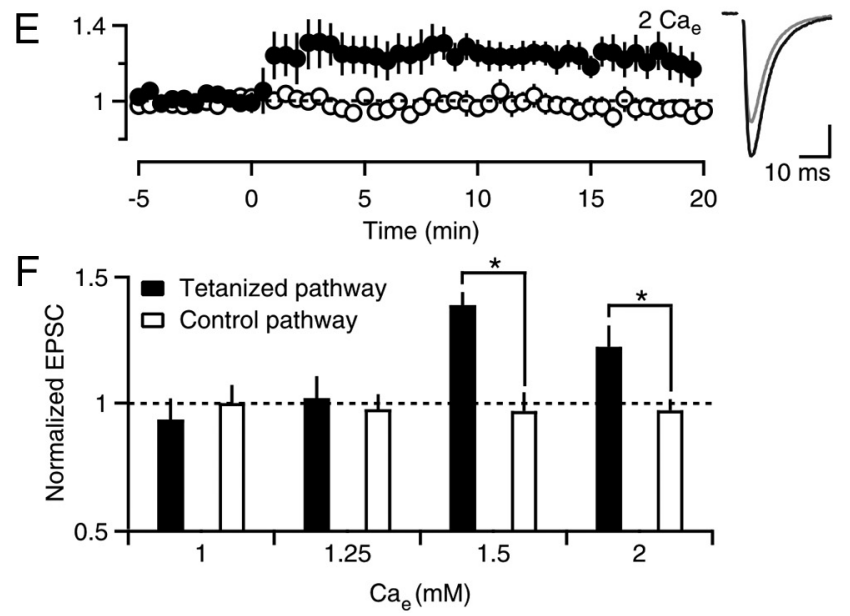

Figure 1. Sensitivity of PF-LTP to external calcium concentration. $A$, A schematic of the recording configuration shows two extracellular electrodes that were used to stimulate independent PF pathways $(0.1 \mathrm{~Hz})$ and a third electrode that was used to measure the amplitude of EPSCs from a PC soma. After a baseline response was determined, a tetanus ( $8 \mathrm{~Hz}, 15 \mathrm{~s}, t=0$ ) was delivered to one pathway, and the other pathway served as a control for recording stability. $\boldsymbol{B}-\boldsymbol{E}$, Left, Experiments were performed in the indicated external calcium concentration $\left(C_{\mathrm{e}}\right)$, and EPSCs were normalized to the amplitude before tetanic stimulation. Six to 10 experiments were averaged for each experimental condition. Filled and open circles indicate tetanized and control pathways, respectively. $\boldsymbol{B}-\boldsymbol{E}$, Right, EPSCs before ( $-5-0 \mathrm{~min}$, gray line) and after (15-20 min, black line) tetanic stimulation are shown for representative experiments in the indicated $\mathrm{C}_{\mathrm{e}}$. Vertical scale bar (in pA): $\boldsymbol{B}$, $38 ; \boldsymbol{C}, 56 ; \boldsymbol{D}, 71 ; \boldsymbol{E}, 172 . \boldsymbol{F}$, Experiments in $\boldsymbol{B}-\boldsymbol{E}$ are summarized, where normalized EPSC amplitudes are plotted for the tetanized pathway (filled bars) and control pathway (open bars). ${ }^{*} p<0.05$ (tetanized pathway vs control, one-way ANOVA).

only produced a short-lived enhancement that was likely due to post-tetanic potentiation (Zucker and Regehr, 2002; Beierlein et al., 2007) and LTP was not observed (1.25 $\mathrm{mM} \mathrm{Ca}_{\mathrm{e}}, 2 \pm 9 \%, n=$ 6 ; $1 \mathrm{mM} \mathrm{Ca}_{\mathrm{e}},-7 \pm 8 \%, n=10$ ) (Fig. $1 \mathrm{~B}, \mathrm{C}$ ). Thus, PF-LTP is steeply dependent on $\mathrm{Ca}_{\mathrm{e}}$ (Fig. $1 F$ ), which suggests that the extent of enhancement is exquisitely sensitive to the magnitude of calcium influx.
A
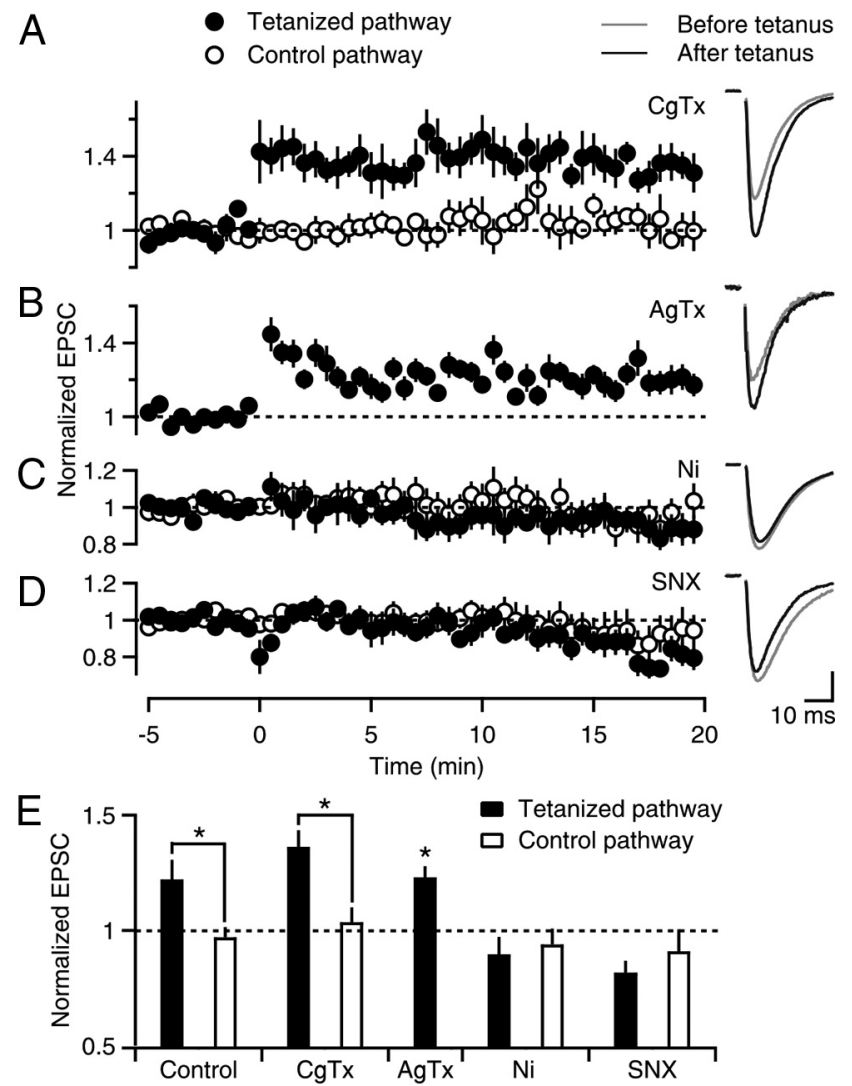

Figure 2. Sensitivity of PF-LTP to calcium channel antagonists. $A-D$, Time courses of normalized EPSCS (left) and example EPSC traces (right) are shown for experiments that were conducted as in Figure 1, except that $\mathrm{Ca}_{\mathrm{e}}$ was $2 \mathrm{~mm}$ and $500 \mathrm{~nm} \omega$-conotoxin GVIA (A), $200 \mathrm{~nm}$ $\omega$-agatoxin IVA $(\boldsymbol{B}), 100 \mu \mathrm{m} \mathrm{NiCl}(\boldsymbol{C})$, or $500 \mathrm{~nm}$ SNX-482 (D) was present. Vertical scale bar (in pA): $\boldsymbol{A}, 138 ; \boldsymbol{B}, 19 ; \boldsymbol{C}, 77 ; \boldsymbol{D}, 191 . \boldsymbol{E}$, Experiments in $\boldsymbol{A}-\boldsymbol{D}$ are summarized. ${ }^{*} p<0.05$ (tetanized pathway vs control, one-way ANOVA). For $\omega$-agatoxin IVA experiments, the tetanized pathway was compared with an idealized value of 1 .

Calcium influx through R-type calcium channels is required for PF-LTP

Multiple types of calcium channels are present on PF boutons: P/Q-type [blocked by $\omega$-agatoxin IVA (AgTx)], N-type [blocked by $\omega$-conotoxin GVIA ( $\mathrm{CgTx})]$, and a component that is insensitive to these toxins (Mintz et al., 1995). T-type calcium channels are not present in cerebellar granule cells (Randall and Tsien, 1995) and L-type calcium channels are not present in PF boutons (Mintz et al., 1995), indicating that this AgTx/CgTx-insensitive component is mediated by R-type calcium channels, which are also known as $\alpha 1_{\mathrm{E}}$ or $\mathrm{CaV}_{2.3}$ calcium channels. R-type calcium channels are blocked by $\mathrm{Ni}^{2+}$ and selectively but incompletely blocked by the peptide toxin SNX-482 (SNX) (Newcomb et al., 1998; Breustedt et al., 2003; Dietrich et al., 2003).

We determined which calcium channel types are important for PF-LTP by examining whether selective antagonists influence LTP induction in $2 \mathrm{mM} \mathrm{Ca}_{\mathrm{e}}$ (Fig. 2). Robust LTP was induced when $\mathrm{N}$-type calcium channels were blocked with $\mathrm{CgTx}$ (36 \pm $7 \%, n=7, p<0.05$, ANOVA) (Fig. $2 A$ ) and when P/Q-type calcium channels were blocked with $\operatorname{AgTx}(23 \pm 4 \%, n=18, p<$ 0.05, ANOVA) (Fig. 2B). This indicates that calcium entry through either N-type or P/Q-type calcium channels is not required for PF-LTP. We examined the component mediated by R-type calcium channels. $\mathrm{Ni}^{2+}$ prevented the induction of LTP $(-10 \pm 8 \%, n=7)$ (Fig. $2 C$ ). Although $\mathrm{Ni}^{2+}$ can also block T-type calcium channels (Lee et al., 1999; Chow et al., 2003; 
A Control
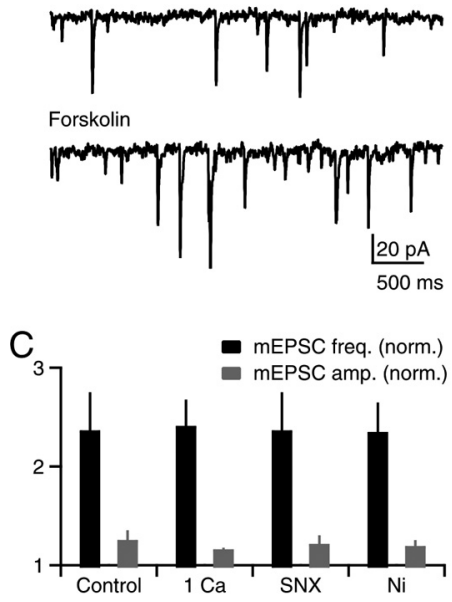

$B$

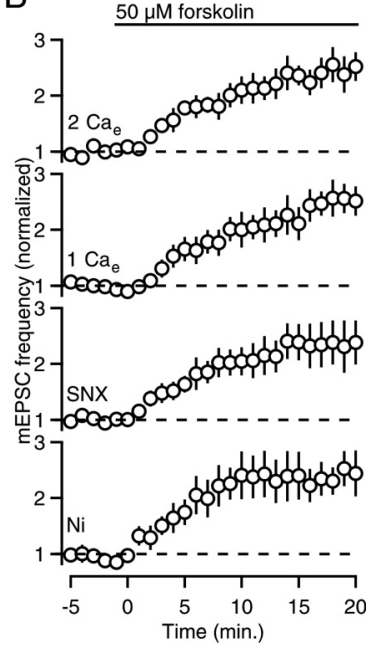

Figure 3. Calcium-sensitivity of CAMP-stimulated mEPSCs. $\boldsymbol{A}$, Example traces of mEPSCS recorded from a $\mathrm{PC}$ in control conditions (top) and after application of forskolin (bottom). $\boldsymbol{B}$,

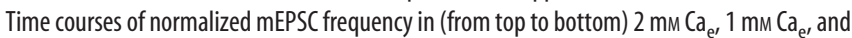
in $2 \mathrm{~mm} \mathrm{Ca}$ with either $500 \mathrm{~nm}$ SNX-482 or $100 \mu \mathrm{M} \mathrm{NiCl}$. $\boldsymbol{C}$, Experiments in $\boldsymbol{B}$ are summarized. $\mathrm{mEPSC}$ frequency (black bars) and amplitude (gray bars) 15-20 min after forskolin application were normalized to control conditions ( -5 to $0 \mathrm{~min}$ ).

Obejero-Paz et al., 2008), because they are not present in cerebellar granule cells (Randall and Tsien, 1995), the $\mathrm{Ni}^{2+}$ sensitivity of PF-LTP is consistent with the involvement of R-type calcium channels. SNX also prevented the induction of LTP $(-19 \pm 5 \%, n=7)$ (Fig. $2 D)$, further indicating that calcium influx through R-type calcium channels, but not $\mathrm{N}$-type or P/Q-type calcium channels, is required to induce PF-LTP (Fig. 2E).

cAMP-dependent plasticity is not sensitive to calcium influx Previous studies have shown that the induction of PF-LTP is triggered by elevations of presynaptic cAMP that stimulate PKA (Salin et al., 1996), which in turn phosphorylates the active zone protein RIM $1 \alpha$ to increase the probability of release (Lonart et al., 2003; but see Kaeser et al., 2008). It is possible to bypass the initial calcium trigger by using forskolin to activate adenylyl cyclase, which elevates presynaptic cAMP levels to enhance both evoked release and spontaneous release (Salin et al., 1996; Chen and Regehr, 1997). We examined forskolin-stimulated mEPSCs to determine whether manipulations that prevent the induction of LTP act on the initial calcium trigger, or act downstream of cAMP production (Fig. 3). In $2 \mathrm{mM} \mathrm{Ca}_{\mathrm{e}}$, forskolin elevated mEPSC frequency $(236 \pm 39 \%$ of control, $n=5)$ (Fig. $3 A, B)$ to a much larger extent than mEPSC amplitude $(126 \pm 10 \%$ of control) (Fig. 3C, gray bars). Forskolin elevated mEPSC frequency to a similar extent in $1 \mathrm{mM} \mathrm{Ca}_{\mathrm{e}}(240 \pm 27 \%$ of control, $n=5)$ in the presence of $\mathrm{Ni}^{2+}(235 \pm 30 \%$ of control, $n=5)$ and in the presence of SNX (236 $\pm 39 \%$ of control, $n=5)$ (Fig. $3 B$ ). These findings indicate that forskolin-stimulated enhancement is unaffected by manipulations that prevent the induction of LTP (Fig. 3C), suggesting that these manipulations suppress LTP by reducing the calcium signal that stimulates $\mathrm{Ca}-\mathrm{AC}$.

R-type calcium channels contribute to synaptic transmission at PF to PC synapses

Our findings thus far indicate that R-type calcium channels play a crucial role in regulating PF-LTP, just as they do for MF-LTP. In

MFs, low-frequency stimulation evokes narrow action potentials that are largely ineffective at opening R-type calcium channels (Alle et al., 2001; Li et al., 2007). As a result, blockade of R-type calcium channels in MFs with either $\mathrm{Ni}^{2+}$ or SNX only modestly reduces presynaptic calcium entry and does not reduce synaptic strength evoked by low-frequency stimulation (Dietrich et al., 2003). During high-frequency stimulation (100 Hz) used to induce MF-LTP, presynaptic action potentials broaden and become more effective at opening R-type calcium channels. As a result, there is significantly more influx through R-type calcium channels during the train compared with low-frequency stimulation. It is thought that facilitation of calcium influx through $\mathrm{R}$-type calcium channels during the induction protocol is important for LTP induction (Dietrich et al., 2003). The role of R-type calcium channels in synaptic transmission has not been determined at PF to PC synapses. We therefore investigated presynaptic calcium signaling by R-type calcium channels in PFs to gain insight into the manner in which R-type calcium channels regulate PF-LTP.

We determined the calcium dependence of synaptic transmission evoked by low-frequency stimulation $(0.1 \mathrm{~Hz})$ (Fig. 4) by measuring the relationship between synaptic strength (EPSC amplitude) (Fig. $4 A)$ and presynaptic calcium influx $\left(\mathrm{Ca}_{\text {influx }}\right)$ (Fig. $4 B$ ) under the manipulations we used in our LTP experiments. We measured presynaptic calcium levels using the low-affinity calcium indicator Magnesium Green as described previously (Mintz et al., 1995; Regehr and Atluri, 1995). These signals provide a measure of the global presynaptic calcium levels in a population of presynaptic boutons and are referred to as $\mathrm{Ca}_{\text {global }}$ (expressed as $\Delta F / F$ ). They do not provide a measure of local signals $\left(\mathrm{Ca}_{\text {local }}\right)$ near open calcium channels. Previous studies have established that the change in $\mathrm{Ca}_{\text {global }}$ evoked by a single action potential is proportional to the total $\mathrm{Ca}_{\text {influx }}$ per action potential (Sabatini and Regehr, 1995). In general, a reduction in calcium entry was correlated with a larger reduction in EPSC amplitude (note the different $y$-axis scales between Fig. 4, $A$ and $B$ ). A double-logarithmic plot of EPSC amplitude versus $\mathrm{Ca}_{\text {influx }}$ (normalized to values obtained in $2 \mathrm{~mm} \mathrm{Ca}_{\mathrm{e}}$ ) illustrates that the relationship between $\mathrm{Ca}_{\text {influx }}$ and synaptic strength can be well approximated by EPSC $=k\left(\mathrm{Ca}_{\text {influx }}\right)^{n}$, where $k$ is a constant, and the peak of the $\mathrm{Ca}_{\text {global }}$ transient following a single action potential provides a measure of $\mathrm{Ca}_{\text {influx }}$ (Fig. $4 C$ ). When $\mathrm{Ca}_{\text {influx }}$ was altered by changing $\mathrm{Ca}_{\mathrm{e}}$ (Fig. $4 A, B$ ), the relationship between synaptic strength (EPSC amplitude) and $\mathrm{Ca}_{\text {influx }}$ was approximated by the above equation with $n \sim 4$ (Fig. $4 C$, open circles). We next investigated the contributions of different types of calcium channels. P/Q-type calcium channels (AgTx-sensitive), which accounted for $\sim 50 \%$ of $\mathrm{Ca}_{\text {influx }}$, were effective at triggering vesicular release $(n \sim 4)$, whereas $\mathrm{N}$-type calcium channels (CgTx-sensitive) contributed a smaller percentage of $\mathrm{Ca}_{\text {influx }}$ $(\sim 25 \%)$ and were less effective at triggering release $(n \sim 2)$. In contrast to MF synapses, R-type calcium channels at PF synapses contribute to low-frequency synaptic transmission. $\mathrm{Ni}^{2+}$ and SNX reduced EPSC amplitude by $38 \pm 5 \%(n=8)$ and $20 \pm 2 \%$ $(n=6)$, respectively, and $\mathrm{Ca}_{\text {influx }}$ by $24 \pm 2 \%(n=6)$ and $9 \pm 2 \%$ $(n=6)$, respectively, such that $2<n<3$ (Fig. $4 C$ ). The smaller effect of SNX compared with $\mathrm{Ni}^{2+}$ likely reflects a less complete block of R-type calcium channels by SNX (Newcomb et al., 1998). However, the finding that R-type calcium channels influence $\mathrm{Ca}_{\text {influx }}$ and synaptic strength suggests that R-type calcium channels may function differently in MFs and PFs. 
A
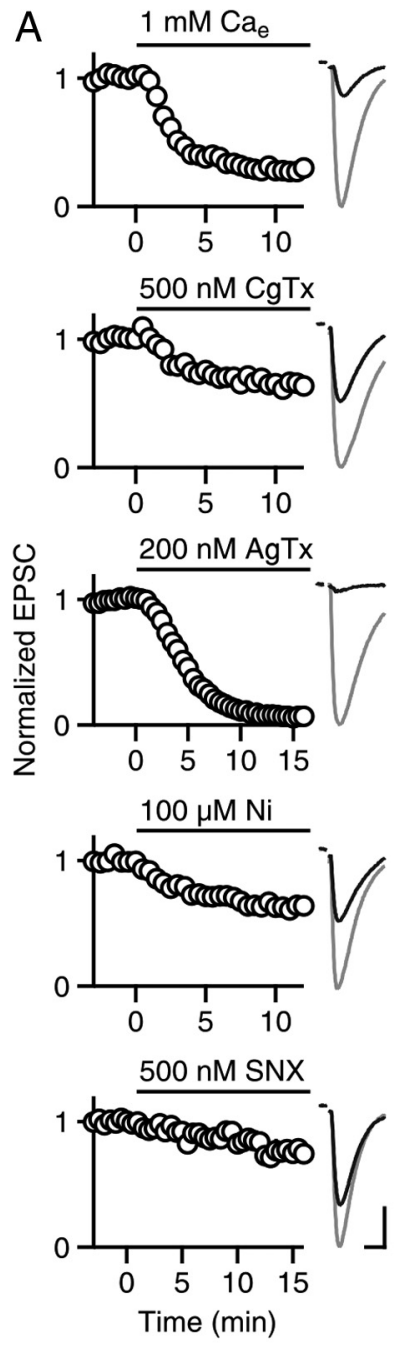

B
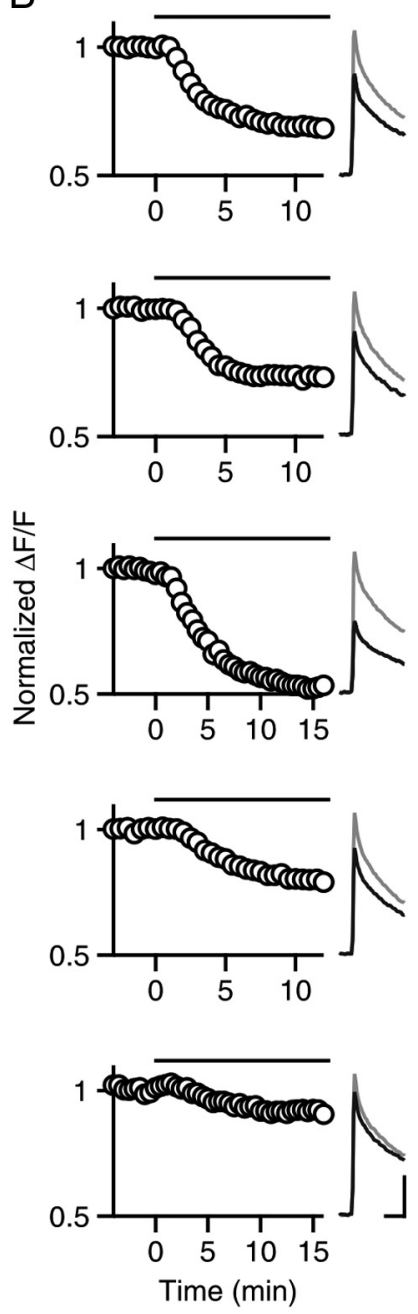

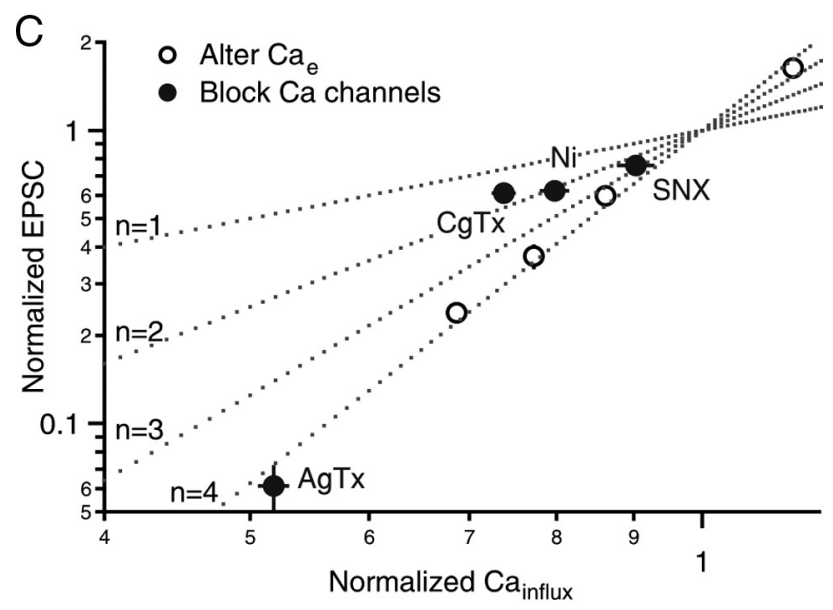

Figure 4. Relationship between calcium influx and synaptic strength. $\boldsymbol{A}, \boldsymbol{B}$, Normalized EP$\mathrm{SCs}(\boldsymbol{A})$ and presynaptic calcium influx $(\boldsymbol{B})$ are shown for (from top to bottom) reducing $\mathrm{Ca}_{\mathrm{e}}$ from 2 to $1 \mathrm{~mm}$ or in $2 \mathrm{~mm} \mathrm{Ca}$ and application of one of the following: $500 \mathrm{~nm} \omega$-conotoxin GVIA, 200 nм $\omega$-agatoxin IVA, $100 \mu \mathrm{m} \mathrm{NiCl}$, or $500 \mathrm{~nm}$ SNX-482. Average time courses (left) and example traces (right) before (gray lines) and after (black lines) are shown for each manipulation (5-7 experiments per manipulation, error bars are occluded by the circles). Horizontal scale bars: $\boldsymbol{A}$, $10 \mathrm{~ms} ; \boldsymbol{B}, 20 \mathrm{~ms}$. Vertical scale bars: $\boldsymbol{A}$ (in pA, from top to bottom), 240, 164, 230, 196, and 151; $\boldsymbol{B}$ (in $\Delta F / F$, from top to bottom), 2.1, 2.1, 1.5, 1.1, and 1.8. C, Normalized EPSCs in $\boldsymbol{A}$ are plotted against normalized calcium influx $\left(\mathrm{Ca}_{\text {influx }}\right)$ in $\boldsymbol{B}$ on $\log _{10}$ scales. Open circles indicate alterations of $\mathrm{Ca}_{\mathrm{e}}$ and filled circles indicate manipulations in $2 \mathrm{~mm} \mathrm{Ca}$. Dotted lines indicate EPSC = $k\left(\mathrm{a}_{\text {influx }}\right)^{n}$, where $n=1,2,3$, and 4 .

\section{R-type calcium channels are not potentiated during the} induction protocol

We went on to measure $\mathrm{Ca}_{\text {global }}$ evoked by the induction protocol (Fig. 5). The stimulus train evoked a series of $\mathrm{Ca}_{\text {global }}$ transients that rapidly decayed to an elevated plateau level between stimuli. After the train, $\mathrm{Ca}_{\text {global }}$ gradually returned to prestimulus levels (Fig. $5 A$ ). In control conditions, the peak $\mathrm{Ca}_{\text {global }}$ levels were $56 \pm 8 \%$ larger than the peak $\mathrm{Ca}_{\text {global }}$ signal evoked by a single stimulus $(n=8)$.

We measured the peak of each transient in the train as well as the plateau and normalized them to the value of the first peak (Fig. 5B, left). Then we performed the manipulations of $\mathrm{Ca}_{\text {influx }}$ as described in Figure 4, and reanalyzed the train, normalizing values to the first peak in control conditions $\left(2 \mathrm{mM} \mathrm{Ca}_{\mathrm{e}}\right)$. An example of reducing $\mathrm{Ca}_{\mathrm{e}}$ to $1 \mathrm{~mm}$ is shown in Figure $5 B$. The peak $\mathrm{Ca}_{\text {global }}$ at the end of the train and integral of $\mathrm{Ca}_{\text {global }}$ during the train were reduced by $\sim 25 \%$ in $1 \mathrm{mM} \mathrm{Ca}_{\mathrm{e}}$, which is slightly less than the reduction in $\mathrm{Ca}_{\text {influx }}$ evoked by a single stimulus ( $30 \%$ ) (Fig. $6 A$ ).

We determined whether our induction protocol preferentially increased calcium entry through R-type calcium channels, as is the case at MF synapses (Dietrich et al., 2003). In these experiments, we evoked trains in control conditions and measured the resulting $\mathrm{Ca}_{\text {global }}$ transients, applied a combination of $\mathrm{CgTx}$ and AgTx and again measured the $\mathrm{Ca}_{\text {global }}$ transients evoked by the train. Based on the insensitivity to CgTx and AgTx and the sensitivity to $\mathrm{Ni}^{2+}$ and $\mathrm{SNX}$, the remaining component is dominated by calcium entry through R-type calcium channels. CgTx and AgTx substantially reduced the peak and plateau $\mathrm{Ca}_{\text {global }}$ signals during the train. We subtracted plateau values from peak values to obtain the magnitude of $\mathrm{Ca}_{\text {influx }}$ for each stimulus in the train (Fig. 5C, bottom). In control conditions and in the presence of the toxins, there was a small enhancement of the $\mathrm{Ca}_{\text {influx }}$ by the end of the train. The signal evoked by the last 5 stimuli in the train divided by the signal evoked by the first stimulus was $1.06 \pm 0.04$ and $1.17 \pm 0.15$ in control conditions and in the presence of CgTx and AgTx, respectively $(n=5)$. These findings suggest that there is a very small $(11 \%)$ increase in the calcium entry through R-type calcium channels during the PF-LTP induction protocol.

\section{Global calcium signaling does not control PF-LTP}

The magnitudes of global presynaptic calcium signals $\left(\mathrm{Ca}_{\text {global }}\right)$ and LTP recorded under different conditions allowed us to assess the role of $\mathrm{Ca}_{\text {global }}$ in the induction of LTP. The effects of altering $\mathrm{Ca}_{\mathrm{e}}$ and blocking specific types of calcium channels on $\mathrm{Ca}_{\text {influx }}$ evoked by single action potentials (Fig. 4), and on the peak $\mathrm{Ca}_{\text {global }}$ and integral of $\mathrm{Ca}_{\text {global }}$ during the induction protocol (Fig. 5), were determined for a variety of experimental conditions (Fig. 6A). In some instances, there were differences in the effects of the manipulations on calcium signaling between single stimuli and the induction protocol. For example, $\mathrm{CgTx}$ had a larger effect on $\mathrm{Ca}_{\text {influx }}$ evoked by single stimuli than on the peak $\mathrm{Ca}_{\text {global }}$ signal evoked by the induction protocol.

We tested whether the calcium dependence of PF-LTP could be explained by changes in $\mathrm{Ca}_{\text {global }}$. Our fluorescence measurements of $\mathrm{Ca}_{\text {global }}$ reflect global calcium rather than $\mathrm{Ca}_{\text {local }}$ (which is exceedingly difficult to measure). We plotted the normalized EPSCs for LTP experiments from Figures 1 and 2 as a function of $\mathrm{Ca}_{\text {influx }}$ of single action potentials from Figure 4 (Fig. $6 \mathrm{~B}$ ), as a function of the peak $\mathrm{Ca}_{\text {global }}$ levels reached during the train (Fig. $6 C)$, and as a function of the integral of $\mathrm{Ca}_{\text {global }}$ evoked by a train (Fig. 6D). If the extent of LTP is controlled by $\mathrm{Ca}_{\text {global }}$, then the magnitude of LTP will depend only upon $\mathrm{Ca}_{\text {global }}$ and there will be a single function describing the relationship between synaptic enhancement and $\mathrm{Ca}_{\text {global. }}$. This was not the case (Fig. $6 B-D$ ). 
When calcium entry was reduced by lowering $\mathrm{Ca}_{\mathrm{e}}$ there was a predicted relationship between plasticity and the global calcium signal (Fig. $6 B-D$, open circles and lines). When calcium entry through specific types of calcium channels was targeted, the extent of LTP did not match the predicted relationship. When P/Q-type calcium channels were blocked with AgTx, there was an extremely large reduction in $\mathrm{Ca}_{\text {global }}$, but plasticity remained. When R-type calcium channels were targeted with SNX or $\mathrm{Ni}^{2+}$, there was a rather small effect on $\mathrm{Ca}_{\text {global }}$, even though LTP was completely blocked (Fig. $6 B-D$ ). In the presence of $\mathrm{Ni}^{2+}$, increasing calcium influx through $\mathrm{N}$-type and $\mathrm{P} / \mathrm{Q}$-type calcium channels by elevating $\mathrm{Ca}_{\mathrm{e}}$ from $2 \mathrm{~mm}$ to $2.5 \mathrm{~mm}$ did not rescue LTP. Thus, the calcium dependence of LTP cannot be accounted for by global presynaptic calcium signaling. The lack of a role for $\mathrm{N}$-type and P/Q-type calcium channels, combined with the crucial role for R-type calcium channels, suggests that calcium entry through R-type calcium channels must act locally to stimulate $\mathrm{Ca}-\mathrm{AC}$ and ultimately induce PF-LTP.

The calcium dependence of LTP at near-physiological temperatures To this point, as in previous studies of presynaptic PF-LTP (Salin et al., 1996; van Beugen et al., 2006), experiments were performed at $25^{\circ} \mathrm{C}$. We went on to test the properties at presynaptic LTP at near-physiological temperatures $\left(34 \pm 1{ }^{\circ} \mathrm{C}\right)$. At these temperatures, tetanic stimulation for $15 \mathrm{~s}$ at $8 \mathrm{~Hz}$ produced a large transient enhancement that lasted for several minutes, but 15-20 min following the tetanus the extent of the enhancement was small ( $7 \pm 6 \%$ compared with $-5 \pm 6 \%$ for the control pathway, $n=$ $9, p=0.09$, paired $t$ test) (Fig. 7A). Prolonged tetanic stimulation $(8 \mathrm{~Hz}, 30 \mathrm{~s})$, as used to examine LTP at PF to stellate cell synapses (Bender et al., 2009), resulted in more pronounced enhancement ( $18 \pm 10 \%$ compared with $-5 \pm 5 \%$ for the control pathway, $n=$ $13, p<0.05$, paired $t$ test) (Fig. $7 B$, top).

We next examined the roles of different types of calcium channels in LTP at near-physiological temperatures. We found that at elevated temperatures, LTP was intact in the presence of the N-type calcium channel blocker $\operatorname{CgTx}(22 \pm 9 \%$ compared with $1 \pm 9 \%$ for the control pathway, $n=12, p<0.01$, paired $t$ test) (Fig. $7 B$, middle), but was absent in the presence of the R-type calcium channel antagonist $\mathrm{Ni}^{2+}(-5 \pm 7 \%$ compared with $-5 \pm 6 \%$ for the control pathway, $n=13, p=0.97$, paired $t$ test) (Fig. $7 B$, bottom). These results are consistent with R-type calcium channels but not $\mathrm{N}$-type calcium channels playing a crucial role in LTP at $34 \pm 1^{\circ} \mathrm{C}$, as was observed at $25 \pm$ $1^{\circ} \mathrm{C}$. It was impractical to examine the role of P/Q-type calcium channels because the synaptic currents remaining in the presence of P/Q-type blockers were too small, and the stability of synaptic currents was inadequate at elevated temperatures.

We went on to examine the contributions of N-type and R-type calcium channels on $\mathrm{Ca}_{\text {global }}$ during the induction protocol to gain insight into the calcium dependence of LTP at elevated temperatures. An example trace shows a typical presynaptic $\mathrm{Ca}_{\text {global }}$ transient evoked by an $8 \mathrm{~Hz}, 30 \mathrm{~s}$ train in control conditions at near-physiological temperatures (Fig. 7C). Stimulus trains were applied first in control
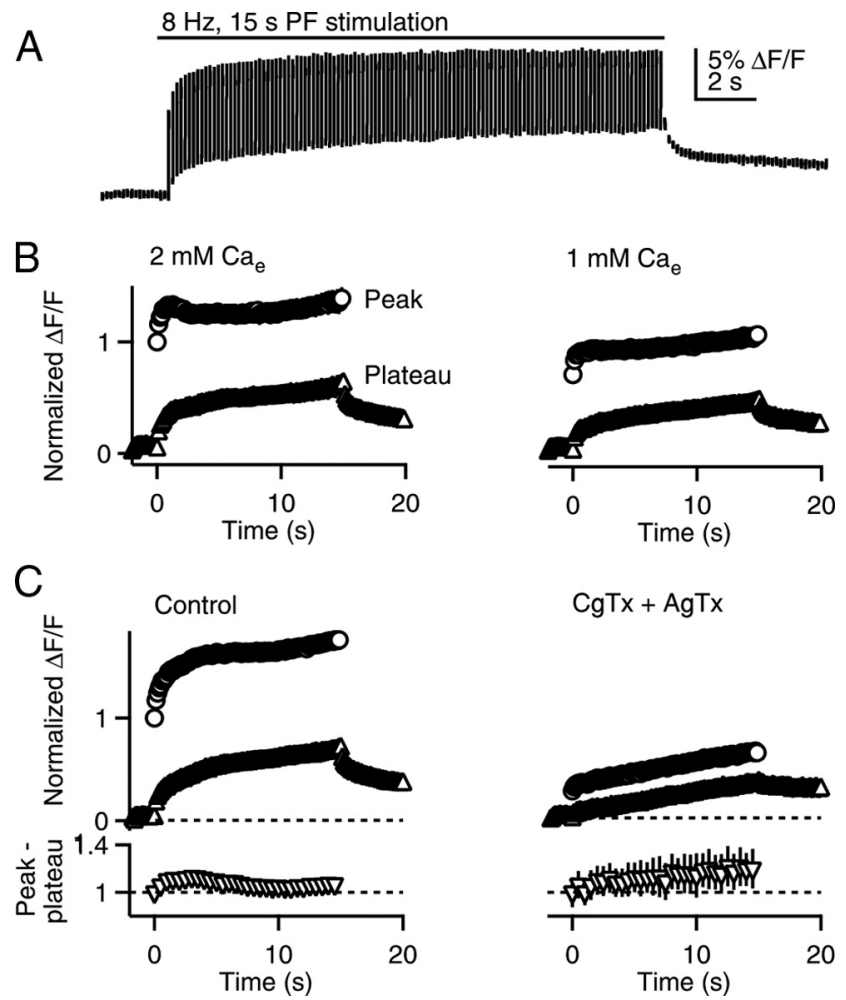

$\operatorname{CgTx}+\operatorname{AgTx}$

Figure 5. Presynaptic calcium signals during the induction protocol. PFs were stimulated (8 $\mathrm{Hz}, 15 \mathrm{~s})$ and global presynaptic calcium signals $\left(\mathrm{Ca}_{\text {global }}\right)$ were measured. $A$, An example $\mathrm{Ca}_{\text {global }}$ transient during the induction protocol is shown. Breaks in the trace indicate times where the excitation was turned off to reduce photobleaching. $B$, Example quantification of $\mathrm{Ca}_{\text {global }}$ during the train in $2 \mathrm{~mm} \mathrm{Ca}_{\mathrm{e}}$ (left) and after washing in $1 \mathrm{~mm} \mathrm{Ca}_{\mathrm{e}}$ (right) is shown ( $n=8$, error bars are occluded by the symbols). Circles, Peaks during the train; triangles, buildup of plateau calcium during the train. C, Quantification of $\mathrm{Ca}_{\text {global }}$ signals before (left) and after (right) application of $500 \mathrm{~nm} \omega$-conotoxin GVIA and $200 \mathrm{~nm} \omega$-agatoxin IVA. The $\mathrm{Ca}_{\text {influx }}$ per spike during the train was determined by subtracting peak values by plateau values for each spike (normalized to the value of the first spike) and is plotted as a function of time for control conditions (lower left) and in the presence of $\omega$-conotoxin GVIA and $\omega$-agatoxin IVA (lower right, $n=5$ ). Each symbol represents an average of five stimuli.

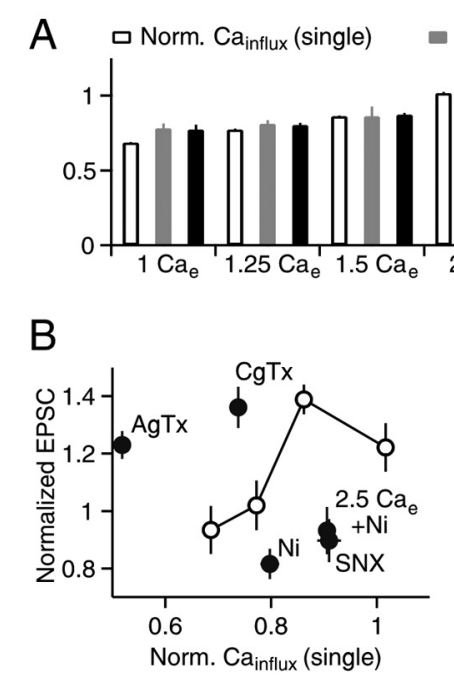

Figure 6. The calcium dependence of PF-LTP. A, Effects of manipulations of calcium entry are summarized for $C a_{\text {influx }}$ during single stimuli (white bars, from Fig. 4 ), for the peak $\mathrm{Ca}_{\text {global }}$ reached in the train (gray bars), and the integral of $\mathrm{Ca}_{\text {global }}$ during the train (black bars). Values are normalized to measurements made in $2 \mathrm{~mm} \mathrm{Ca}_{\mathrm{e}}$ and represent the averages of four to seven experiments. $\boldsymbol{B}-\boldsymbol{D}$, Normalized EPSCs from LTP experiments (Figs. 1, 2) are plotted against $\mathrm{Ca}_{\text {influx }}$ for single stimuli $(\boldsymbol{B})$, peak $\mathrm{Ca}_{\text {global }}$ during the induction protocol $(\boldsymbol{C})$, and the integral of $C_{a_{\text {global }}}$ during the induction protocol $(\boldsymbol{D})$. Open circles connected by lines, Manipulations of $\mathrm{Ca}_{\mathrm{e}}$; filled circles, blockade of specific calcium channels. 

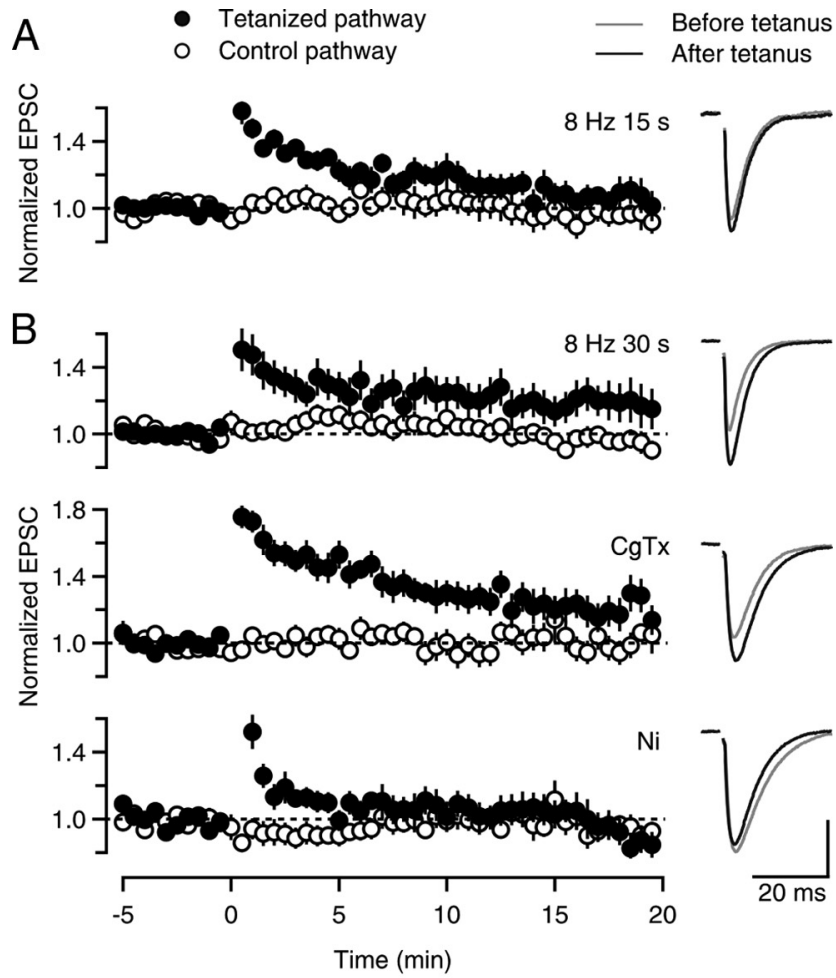

C $8 \mathrm{~Hz}, 30 \mathrm{~s}$ PF stimulation
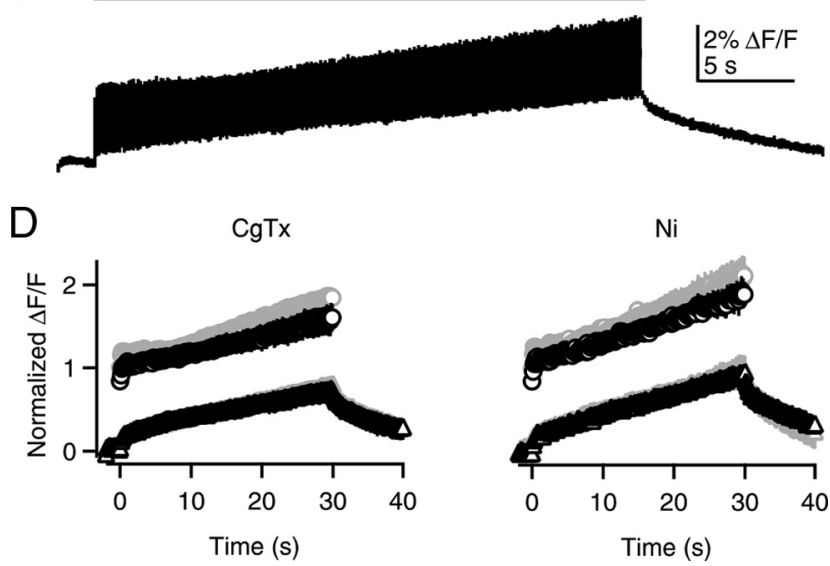

Figure 7. PF-LTP and presynaptic calcium signals at near-physiological temperatures. $\boldsymbol{A}, \boldsymbol{B}$, Time courses of normalized EPSCs (left) and example EPSC traces (right) are shown for LTP experiments conducted at $34 \pm 1^{\circ} \mathrm{C}$. $\boldsymbol{A}$, LTP was induced with an $8 \mathrm{~Hz}, 15$ s tetanus at $t=0 . \boldsymbol{B}$, LTP was induced with an $8 \mathrm{~Hz}, 30$ s tetanus at $t=0$ in control conditions (top), in the presence of $500 \mathrm{~nm} \omega$-conotoxin GVIA (middle), or $100 \mu \mathrm{m} \mathrm{NiCl}$ (bottom). Vertical scale bar: $\boldsymbol{A}, 95 \mathrm{pA} ; \boldsymbol{B}$ (from top to bottom), 293, 186, and $176 \mathrm{pA}$. C, An example $\mathrm{Ca}_{\text {global }}$ transient during an $8 \mathrm{~Hz}, 30 \mathrm{~s}$ tetanus is shown. D, Quantification of $\mathrm{Ca}_{\text {global }}$ peaks during the train (circles) and buildup of plateau calcium during the train (triangles) before (gray symbols) and after (black symbols) application of $500 \mathrm{~nm} \omega$-conotoxin GVIA (left) or $100 \mu \mathrm{m} \mathrm{NiCl}$ (right).

conditions and then the presence of a calcium channel antagonist (Fig. $7 D$ ). We found that the peak $\mathrm{Ca}_{\text {global }}$ levels reached in the presence of $\mathrm{CgTx}$ and $\mathrm{Ni}^{2+}$ relative to control conditions were $0.86 \pm$ $0.08(n=5)$ and $0.89 \pm 0.07(n=5)$, respectively. These results are summarized in Figure $7 D$, where the average peak $\mathrm{Ca}_{\text {global }}$ signals evoked during the train in the presence of calcium channel blockers are expressed relative to the amplitude of the $\mathrm{Ca}_{\text {global }}$ signal evoked by low-frequency stimulation in control conditions. In contrast, the magnitude of calcium signals evoked by the second of two trains in control conditions was unchanged (peak calcium levels at the end of the second train, $1.03 \pm 0.06$ of the amplitude at the end of the first train; $n=8$; data not shown).

Together, these results indicate that the crucial role of R-type but not N-type calcium channels in the induction of LTP cannot be explained by $\mathrm{Ca}_{\text {global}}$, because $\mathrm{CgTx}$ and $\mathrm{Ni}^{2+}$ have approximately the same effect on global presynaptic calcium signals. Thus, the basic finding that local calcium signaling through R-type calcium triggers PF-LTP holds at near-physiological temperatures.

\section{Discussion}

We found that, although most presynaptic calcium enters PFs through N-type and P/Q-type calcium channels, neither channel regulates the induction of PF-LTP under our experimental conditions. Instead, calcium entry through R-type calcium channels induces PF-LTP, even though these channels contribute a small fraction of overall calcium entry during the induction protocol. Modulation of global calcium signaling cannot account for the observed calcium dependence of PF-LTP. We conclude that R-type calcium channels act within presynaptic boutons to activate $\mathrm{Ca}-\mathrm{AC}$ through functional calcium microdomains, thereby inducing PF-LTP.

\section{The calcium sensitivity of PF-LTP}

Experiments in which presynaptic calcium influx was systematically altered by changing $\mathrm{Ca}_{\mathrm{e}}$ revealed that PF-LTP is steeply calcium-dependent. Reducing $\mathrm{Ca}_{\mathrm{e}}$ from 1.5 to $1.25 \mathrm{~mm}$ decreased $\mathrm{Ca}_{\text {influx }}$ through all calcium channels by just $10 \%$, but prevented the induction of PF-LTP (Fig. $1 B, C$ ). This steep calcium dependence is compatible with the high cooperativity of the activation of Ca-AC by calmodulin, which has four calcium binding sites (Olwin et al., 1984; Iida and Potter, 1986).

Using an approach that has been used previously to distinguish between $\mathrm{Ca}_{\text {local }}$ and $\mathrm{Ca}_{\text {global }}$ signaling (Yasuda et al., 2003; Berridge, 2006; Bloodgood and Sabatini, 2007), we established that calcium microdomains near R-type calcium channels play a crucial role in presynaptic PF-LTP. The relationship between the magnitude of synaptic enhancement and the magnitude of $\mathrm{Ca}_{\text {global }}$ indicated that regulation of global presynaptic calcium signaling does not explain the calcium dependence of PF-LTP. Blocking P/Q-type calcium channels with AgTx, which reduced $\mathrm{Ca}_{\text {global }}$ by almost $50 \%$, did not block LTP. However, blocking R-type calcium channels with SNX, which only reduced $\mathrm{Ca}_{\text {global }}$ by $9 \%$, completely blocked LTP. These findings indicate that LTP is evoked by calcium influx specifically through R-type calcium channels. Moreover, they establish that calcium-stimulation of AC1 and AC8 must reflect local calcium microdomains and suggest that R-type calcium channels and $\mathrm{Ca}-\mathrm{AC}$ are closely associated within PF boutons.

\section{Local calcium signaling and $\mathrm{Ca}-\mathrm{AC}$ activation}

A direct association between $\mathrm{Ca}-\mathrm{AC}$ and $\mathrm{R}$-type calcium channels has not been reported, but there is evidence that $\mathrm{AC} 1$ and $\mathrm{AC} 8$ can be functionally localized to sources of calcium influx that stimulate them (Crossthwaite et al., 2005; Hall et al., 2007; Piggott et al., 2008). In heterologous systems, $\mathrm{AC} 1$ and AC8 are stimulated by capacitative calcium entry, but not by calcium released from intracellular stores (Masada et al., 2009; Willoughby et al., 2010). AC1 and AC8 are also sensitive to calcium influx through voltage-gated calcium channels (Fagan et al., 2000), but the subtype specificity of this mechanism has not been investigated.

The manner in which a calcium microdomain produced by R-type calcium channels stimulates $\mathrm{Ca}$-AC under physiological conditions is complex. Both AC1 and AC8 can be activated by modest, sustained increases in calcium $\left(\mathrm{EC}_{50}\right.$ of $150-190 \mathrm{nM}$ and $320-560$ 
nM, respectively) (Cimler et al., 1985; Wayman et al., 1994). These values are substantially lower than what likely occurs at the pore of the channel (10-100 $\mu \mathrm{M})$ (Fogelson and Zucker, 1985; Simon and Llinas, 1985; Augustine and Neher, 1992; Stern, 1992; Zucker and Regehr, 2002). However, it is unlikely that, in our studies, the transient elevations of $\mathrm{Ca}_{\text {global }}$ produced by the induction protocol are long enough to reach steady-state activation of Ca-AC. This is consistent with our observation that global calcium signals produced by such trains are not sufficient to explain the calcium dependence of PF-LTP (Fig. 6B-D). Instead, it appears that $\mathrm{Ca}_{\text {local }}$ near R-type calcium channels is large enough to activate $\mathrm{Ca}-\mathrm{AC}$ sufficiently to induce PF-LTP. The modest calcium requirement for activation of $\mathrm{Ca}-\mathrm{AC}$ also suggests that R-type calcium channels and Ca-AC might not need to be particularly closely associated, and that a local calcium signal at $\sim 100 \mathrm{~nm}$ from an R-type calcium channel might be sufficient to activate Ca-AC (Fogelson and Zucker, 1985; Simon and Llinas, 1985; Augustine and Neher, 1992; Zucker and Regehr, 2002). The properties of R-type calcium channel microdomain activation that we report here for $\mathrm{Ca}-\mathrm{AC}$ in presynaptic terminals is similar in many ways to the activation of SK channels in postsynaptic spines (Bloodgood and Sabatini, 2007). In both cases, the calcium sensor is calmodulin, activation is steeply calcium-dependent, and halfmaximal steady-state activation occurs for calcium increases of several hundred nanomolar (Wu et al., 1993; Xia et al., 1998; Li and Aldrich, 2009).

\section{R-type calcium channels and cAMP-dependent presynaptic LTP}

Our finding that R-type calcium channels are involved in PF-LTP, along with previous studies establishing the involvement of R-type calcium channels in MF-LTP (Breustedt et al., 2003; Dietrich et al., 2003), suggests a general role for R-type calcium channels in cAMPdependent presynaptic LTP. There are, however, important differences in the contributions of R-type calcium channels to synaptic transmission and presynaptic calcium signaling between MF and PF synapses. First, R-type calcium channels in MFs are not effectively opened by low-frequency stimulation and do not contribute to basal synaptic transmission (Dietrich et al., 2003; but see Gasparini et al., 2001), whereas R-type calcium channels in PFs contribute to lowfrequency transmission with $2<n<3$ (Fig. 4). Second, during the tetanic stimulation used to induce MF-LTP, presynaptic spike broadening occurs, which more effectively opens R-type calcium channels (Li et al., 2007). This allows R-type calcium channels in MFs to make a more substantial contribution to calcium entry by the end of the train compared with low-frequency stimulation. In contrast, $\mathrm{Ca}_{\text {influx }}$ through R-type calcium channels in PFs is increased by just $11 \%$ by the end of the induction protocol.

Finally, MF-LTP is thought to be controlled by a $\mathrm{Ca}_{\text {global }}$ (Dietrich et al., 2003), whereas we find that PF-LTP is regulated by $\mathrm{Ca}_{\text {local }}$. The apparent differences in the roles of $\mathrm{Ca}_{\text {global }}$ and $\mathrm{Ca}_{\text {local }}$ between MF and PF synapses may be a consequence of the stimulus frequency used to induce LTP $(100 \mathrm{~Hz}$ at MF synapses vs $8 \mathrm{~Hz}$ at PF synapses). During high-frequency trains, $\mathrm{Ca}_{\text {global }}$ may be sufficient to activate $\mathrm{Ca}-\mathrm{AC}$ and $\mathrm{Ca}_{\text {local }}$ signals near open $\mathrm{R}$-type calcium channels may not be essential. It may be that only moderate frequency induction protocols require local calcium increases to activate $\mathrm{Ca}-\mathrm{AC}$ and induce LTP. This raises the possibility that $\mathrm{Ca}_{\text {local }}$ might also be crucial to induce MF-LTP with moderate frequency induction trains.

\section{Implications for the regulation of PF-LTP}

G-protein-coupled receptors could regulate PF-LTP by inhibiting cAMP production either through direct actions on Ca-AC, or indirectly by reducing the calcium signal available to activate Ca-AC (van Beugen et al., 2006). Our findings, combined with our previous finding that CB1R activation reduces calcium entry through R-type calcium channels (Brown et al., 2004), suggest that the modulation of R-type calcium channels may contribute to the disruption of PF-LTP by activation of presynaptic CB1Rs. Moreover, it seems likely that any neuromodulator that inhibits presynaptic R-type calcium channels (Dittman and Regehr, 1996) will also regulate the induction of PF-LTP.

\section{Regulation of presynaptic LTP by calcium microdomains}

Our major finding is that local calcium signaling through microdomains near R-type calcium channels is important for presynaptic LTP. The fact that R-type calcium channels can control LTP postsynaptically (Stackman et al., 2002; Bond et al., 2004; Ngo-Anh et al., 2005; Hammond et al., 2006) and presynaptically as a consequence of local calcium interactions with calmodulin suggest a widespread role for R-type calcium channels in regulating calmodulin-sensitive cellular processes.

\section{References}

Alle H, Jonas P, Geiger JR (2001) PTP and LTP at a hippocampal mossy fiber-interneuron synapse. Proc Natl Acad Sci U S A 98:14708-14713.

Augustine GJ, Neher E (1992) Neuronal Ca2+ signalling takes the local route. Curr Opin Neurobiol 2:302-307.

Beierlein M, Fioravante D, Regehr WG (2007) Differential expression of posttetanic potentiation and retrograde signaling mediate targetdependent short-term synaptic plasticity. Neuron 54:949-959.

Bender VA, Pugh JR, Jahr CE (2009) Presynaptically expressed long-term potentiation increases multivesicular release at parallel fiber synapses. J Neurosci 29:10974-10978.

Berridge MJ (2006) Calcium microdomains: organization and function. Cell Calcium 40:405-412.

Bloodgood BL, Sabatini BL (2007) Nonlinear regulation of unitary synaptic signals by $\mathrm{CaV}(2.3)$ voltage-sensitive calcium channels located in dendritic spines. Neuron 53:249-260.

Bond CT, Herson PS, Strassmaier T, Hammond R, Stackman R, Maylie J, Adelman JP (2004) Small conductance Ca2+-activated K+ channel knock-out mice reveal the identity of calcium-dependent afterhyperpolarization currents. J Neurosci 24:5301-5306.

Breustedt J, Vogt KE, Miller RJ, Nicoll RA, Schmitz D (2003) Alpha1Econtaining $\mathrm{Ca} 2+$ channels are involved in synaptic plasticity. Proc Natl Acad Sci U S A 100:12450-12455.

Brown SP, Safo PK, Regehr WG (2004) Endocannabinoids inhibit transmission at granule cell to Purkinje cell synapses by modulating three types of presynaptic calcium channels. J Neurosci 24:5623-5631.

Castillo PE, Weisskopf MG, Nicoll RA (1994) The role of Ca2+ channels in hippocampal mossy fiber synaptic transmission and long-term potentiation. Neuron 12:261-269.

Chen C, Regehr WG (1997) The mechanism of cAMP-mediated enhancement at a cerebellar synapse. J Neurosci 17:8687-8694.

Chow KY, Wu C, Sui GP, Fry CH (2003) Role of the T-type Ca2+ current on the contractile performance of guinea pig detrusor smooth muscle. Neurourol Urodyn 22:77-82.

Cimler BM, Andreasen TJ, Andreasen KI, Storm DR (1985) P-57 is a neural specific calmodulin-binding protein. J Biol Chem 260:10784-10788.

Crossthwaite AJ, Seebacher T, Masada N, Ciruela A, Dufraux K, Schultz JE, Cooper DM (2005) The cytosolic domains of Ca2+-sensitive adenylyl cyclases dictate their targeting to plasma membrane lipid rafts. J Biol Chem 280:6380-6391.

Dietrich D, Kirschstein T, Kukley M, Pereverzev A, von der Brelie C, Schneider T, Beck H (2003) Functional specialization of presynaptic Cav2.3 Ca2 + channels. Neuron 39:483-496.

Dittman JS, Regehr WG (1996) Contributions of calcium-dependent and calcium-independent mechanisms to presynaptic inhibition at a cerebellar synapse. J Neurosci 16:1623-1633.

Fagan KA, Graf RA, Tolman S, Schaack J, Cooper DM (2000) Regulation of a Ca2+-sensitive adenylyl cyclase in an excitable cell: role of voltage-gated versus capacitative Ca2+ entry. J Biol Chem 275:40187-40194. 
Fakler B, Adelman JP (2008) Control of K(Ca) channels by calcium nano/ microdomains. Neuron 59:873-881.

Fogelson AL, Zucker RS (1985) Presynaptic calcium diffusion from various arrays of single channels: implications for transmitter release and synaptic facilitation. Biophys J 48:1003-1017.

Fourcaudot E, Gambino F, Humeau Y, Casassus G, Shaban H, Poulain B, Lüthi A (2008) cAMP/PKA signaling and RIMlalpha mediate presynaptic LTP in the lateral amygdala. Proc Natl Acad Sci U S A 105:15130-15135.

Gasparini S, Kasyanov AM, Pietrobon D, Voronin LL, Cherubini E (2001) Presynaptic R-type calcium channels contribute to fast excitatory synaptic transmission in the rat hippocampus. J Neurosci 21:8715-8721.

Hall DD, Davare MA, Shi M, Allen ML, Weisenhaus M, McKnight GS, Hell JW (2007) Critical role of cAMP-dependent protein kinase anchoring to the L-type calcium channel Cav1.2 via A-kinase anchor protein 150 in neurons. Biochemistry 46:1635-1646.

Hammond RS, Bond CT, Strassmaier T, Ngo-Anh TJ, Adelman JP, Maylie J, Stackman RW (2006) Small-conductance Ca2+-activated K+ channel type 2 (SK2) modulates hippocampal learning, memory, and synaptic plasticity. J Neurosci 26:1844-1853.

Higley MJ, Sabatini BL (2008) Calcium signaling in dendrites and spines: practical and functional considerations. Neuron 59:902-913.

Iida S, Potter JD (1986) Calcium binding to calmodulin: cooperativity of the calcium-binding sites. J Biochem 99:1765-1772.

Kaeser PS, Kwon HB, Blundell J, Chevaleyre V, Morishita W, Malenka RC, Powell CM, Castillo PE, Südhof TC (2008) RIMlalpha phosphorylation at serine- 413 by protein kinase $\mathrm{A}$ is not required for presynaptic longterm plasticity or learning. Proc Natl Acad Sci U S A 105:14680-14685.

Lee JH, Gomora JC, Cribbs LL, Perez-Reyes E (1999) Nickel block of three cloned T-type calcium channels: low concentrations selectively block alphalH. Biophys J 77:3034-3042.

Li L, Bischofberger J, Jonas P (2007) Differential gating and recruitment of $\mathrm{P} / \mathrm{Q}-, \mathrm{N}$-, and R-type Ca2 + channels in hippocampal mossy fiber boutons. J Neurosci 27:13420-13429.

Li W, Aldrich RW (2009) Activation of the SK potassium channelcalmodulin complex by nanomolar concentrations of terbium. Proc Natl Acad Sci U S A 106:1075-1080.

Liu HN, Kurotani T, Ren M, Yamada K, Yoshimura Y, Komatsu Y (2004) Presynaptic activity and Ca2 + entry are required for the maintenance of NMDA receptor-independent LTP at visual cortical excitatory synapses. J Neurophysiol 92:1077-1087.

Lonart G, Schoch S, Kaeser PS, Larkin CJ, Südhof TC, Linden DJ (2003) Phosphorylation of RIMlalpha by PKA triggers presynaptic long-term potentiation at cerebellar parallel fiber synapses. Cell 115:49-60.

Maffei A, Prestori F, Rossi P, Taglietti V, D’Angelo E (2002) Presynaptic current changes at the mossy fiber-granule cell synapse of cerebellum during LTP. J Neurophysiol 88:627-638.

Masada N, Ciruela A, Macdougall DA, Cooper DM (2009) Distinct mechanisms of regulation by $\mathrm{Ca} 2+/$ calmodulin of type 1 and 8 adenylyl cyclases support their different physiological roles. J Biol Chem 284:4451-4463.

Mintz IM, Sabatini BL, Regehr WG (1995) Calcium control of transmitter release at a cerebellar synapse. Neuron 15:675-688.

Newcomb R, Szoke B, Palma A, Wang G, Chen X, Hopkins W, Cong R, Miller J, Urge L, Tarczy-Hornoch K, Loo JA, Dooley DJ, Nadasdi L, Tsien RW, Lemos J, Miljanich G (1998) Selective peptide antagonist of the class E calcium channel from the venom of the tarantula Hysterocrates gigas. Biochemistry 37:15353-15362.

Ngo-Anh TJ, Bloodgood BL, Lin M, Sabatini BL, Maylie J, Adelman JP (2005) SK channels and NMDA receptors form a Ca2+-mediated feedback loop in dendritic spines. Nat Neurosci 8:642-649.

Nicoll RA, Schmitz D (2005) Synaptic plasticity at hippocampal mossy fibre synapses. Nat Rev Neurosci 6:863-876.

Obejero-Paz CA, Gray IP, Jones SW (2008) Ni2+ block of CaV3.1 (alpha1G) T-type calcium channels. J Gen Physiol 132:239-250.

Olwin BB, Edelman AM, Krebs EG, Storm DR (1984) Quantitation of energy coupling between $\mathrm{Ca} 2+$, calmodulin, skeletal muscle myosin light chain kinase, and kinase substrates. J Biol Chem 259:10949-10955.

Piggott LA, Bauman AL, Scott JD, Dessauer CW (2008) The A-kinase anchoring protein Yotiao binds and regulates adenylyl cyclase in brain. Proc Natl Acad Sci U S A 105:13835-13840.

Randall A, Tsien RW (1995) Pharmacological dissection of multiple types of $\mathrm{Ca} 2+$ channel currents in rat cerebellar granule neurons. J Neurosci 15:2995-3012.
Regehr WG, Atluri PP (1995) Calcium transients in cerebellar granule cell presynaptic terminals. Biophys J 68:2156-2170.

Regehr WG, Tank DW (1991) Selective fura-2 loading of presynaptic terminals and nerve cell processes by local perfusion in mammalian brain slice. J Neurosci Methods 37:111-119.

Rizzuto R, Pozzan T (2006) Microdomains of intracellular Ca2+: molecular determinants and functional consequences. Physiol Rev 86:369-408.

Sabatini BL, Regehr WG (1995) Detecting changes in calcium influx which contribute to synaptic modulation in mammalian brain slice. Neuropharmacology 34:1453-1467.

Sabatini BL, Regehr WG (1998) Optical measurement of presynaptic calcium currents. Biophys J 74:1549-1563.

Salin PA, Malenka RC, Nicoll RA (1996) Cyclic AMP mediates a presynaptic form of LTP at cerebellar parallel fiber synapses. Neuron 16:797-803.

Shan Q, Chan GC, Storm DR (2008) Type 1 adenylyl cyclase is essential for maintenance of remote contextual fear memory. J Neurosci $28: 12864-12867$.

Simon SM, Llinás RR (1985) Compartmentalization of the submembrane calcium activity during calcium influx and its significance in transmitter release. Biophys J 48:485-498.

Stackman RW, Hammond RS, Linardatos E, Gerlach A, Maylie J, Adelman JP, Tzounopoulos T (2002) Small conductance Ca2+-activated K+ channels modulate synaptic plasticity and memory encoding. J Neurosci 22:10163-10171

Stern MD (1992) Buffering of calcium in the vicinity of a channel pore. Cell Calcium 13:183-192.

Storm DR, Hansel C, Hacker B, Parent A, Linden DJ (1998) Impaired cerebellar long-term potentiation in type I adenylyl cyclase mutant mice. Neuron 20:1199-1210.

van Beugen BJ, Nagaraja RY, Hansel C (2006) Climbing fiber-evoked endocannabinoid signaling heterosynaptically suppresses presynaptic cerebellar long-term potentiation. J Neurosci 26:8289-8294.

Wang H, Pineda VV, Chan GC, Wong ST, Muglia LJ, Storm DR (2003) Type 8 adenylyl cyclase is targeted to excitatory synapses and required for mossy fiber long-term potentiation. J Neurosci 23:9710-9718.

Wang X, Chen G, Gao W, Ebner T (2009) Long-term potentiation of the responses to parallel fiber stimulation in mouse cerebellar cortex in vivo. Neuroscience 162:713-722.

Wayman GA, Impey S, Wu Z, Kindsvogel W, Prichard L, Storm DR (1994) Synergistic activation of the type I adenylyl cyclase by Ca2+ and Gscoupled receptors in vivo. J Biol Chem 269:25400-25405.

Willoughby D, Wachten S, Masada N, Cooper DM (2010) Direct demonstration of discrete $\mathrm{Ca} 2+$ microdomains associated with different isoforms of adenylyl cyclase. J Cell Sci 123:107-117.

Wong ST, Athos J, Figueroa XA, Pineda VV, Schaefer ML, Chavkin CC, Muglia LJ, Storm DR (1999) Calcium-stimulated adenylyl cyclase activity is critical for hippocampus-dependent long-term memory and late phase LTP. Neuron 23:787-798.

Wu Z, Wong ST, Storms DR (1993) Modification of the calcium and calmodulin sensitivity of the type I adenylyl cyclase by mutagenesis of its calmodulin binding domain. J Biol Chem 268:23766-23768.

Wu ZL, Thomas SA, Villacres EC, Xia Z, Simmons ML, Chavkin C, Palmiter $\mathrm{RD}$, Storm DR (1995) Altered behavior and long-term potentiation in type I adenylyl cyclase mutant mice. Proc Natl Acad Sci U S A 92:220-224.

Xia XM, Fakler B, Rivard A, Wayman G, Johnson-Pais T, Keen JE, Ishii T, Hirschberg B, Bond CT, Lutsenko S, Maylie J, Adelman JP (1998) Mechanism of calcium gating in small-conductance calcium-activated potassium channels. Nature 395:503-507.

Yasuda R, Sabatini BL, Svoboda K (2003) Plasticity of calcium channels in dendritic spines. Nat Neurosci 6:948-955.

Yuste R, Konnerth A (2005) Imaging in neuroscience and development: a laboratory manual, pp. 307-314. Cold Spring Harbor, New York: Cold Spring Harbor Laboratory.

Zalutsky RA, Nicoll RA (1990) Comparison of two forms of long-term potentiation in single hippocampal neurons. Science 248:1619-1624.

Zhang M, Moon C, Chan GC, Yang L, Zheng F, Conti AC, Muglia L, Muglia LJ, Storm DR, Wang H (2008) Ca-stimulated type 8 adenylyl cyclase is required for rapid acquisition of novel spatial information and for working/episodic-like memory. J Neurosci 28:4736-4744.

Zucker RS, Regehr WG (2002) Short-term synaptic plasticity. Annu Rev Physiol 64:355-405. 